\title{
Flexibilität, Fehlzeiten und Führung
}

Die aktuellen Diskussionen über die wirtschaftliche Entwicklung, und über die steigende Zahl der Arbeitsplatzlosen legen Defizite offen, über die in manchen Ländern wie Holland, Neuseeland und Schweden kaum noch argumentiert wird, denn dort ist die erstrebte "Wende“ eingetreten.

Mangelnde Flexibilit, Besitzstanddenken und Führungsschwächen herrschen leider immer noch bei uns vor. Allenthalben werden heute immer mehr Flexibilität und Kreativität gefordert. Das ist auch gut so, denn die gesellschaftliche und technische Entwicklung verlangt Umstellungen in immer kürzeren Zeiträumen.

Nun sind aber die Menschen nicht so leicht zu verändern, wie wir es besonders in den ehemals kommunistischen Ländern spüren. $\mathrm{Zu}$ dem vorhandenen natürlichen Beharrungsvermögen kommt die Angst vor der Veränderung.

Was wollen wir aber von den Mitarbeitern erwarten, wenn die Vorgesetzten oft mit schlechtem Beispiel vorangehen? Das stellen besonders große Firmen bei Organisationsveränderungen und bei notwendigen Umzügen fest. Ein sehr negatives Beispiel ist die Verlagerung der Hauptstadtaktivitäten nach Berlin. Was sich in diesem Zusammenhang viele Menschen leisten, steht nicht nur im Widerspruch zu unserer wirtschaftlichen Situation, sondern auch zu den Anstellungsbedingungen. Immer wieder erlebe ich, wie flexibel Führungskräfte z.B. der Bundeswehr oder des Auswärtigen Amts sind. Sie müssen so oft den Wohnort, manchmal sogar ins Ausland, wechseln wie Führungskräfte in internationalen Konzernen oder Mitarbeiter im Vertrieb. Kurt Tucholsky vermutete bei den Deutschen eine besondere Charaktereigenschaft: "Wenn der Deutsche hinfällt, dann steht er nicht auf, sondern schaut, wer schadensersatzpflichtig ist."

Als ich mit meinen in- und ausländischen Studierenden eine große Bank besuchte, erläuterte uns der Leiter, wie Kreativität und Flexibilität möglichst vieler Mitarbeiter in die tägliche Arbeit einfließen sollen. Formalismus müsse weiter abgebaut werden, Querdenker seien gefragt, und der Kunde muß stärker im Mittelpunkt stehen.

Das gilt besonders für die Länder, die von der zentralen Planwirtschaft zur Marktwirtschaft wechselten. Welche vielschichtigen Probleme bei Dozenten und Studenten dabei auftreten, habe ich besonders an den Universitäten in Alma Ata, Minsk und Murmansk erlebt.

Es sind aber auch ermutigend Ansätze festzustellen. Dennoch bleibt viel zu tun. In den Unternehmen ist dieses gemeinsam mit den Sozialpartnern erreichbar, wenn Probleme erkannt sind und alle eine gemeinsame für die Wirtschaft und die Gesellschaft notwendige Lösung anstreben.

Ernst Zander, Universität Hamburg 
